\title{
Acknowledgement to Reviewers of Journal of Developmental Biology in 2015
}

\author{
Journal of Developmental Biology Editorial Office \\ MDPI AG, Klybeckstrasse 64, CH-4057 Basel, Switzerland; jdb@mdpi.com \\ Published: 25 January 2016
}

The editors of Journal of Developmental Biology would like to express their sincere gratitude to the following reviewers for assessing manuscripts in 2015.

We greatly appreciate the contribution of expert reviewers, which is crucial to the journal's editorial decision-making process. Several steps have been taken in 2015 to thank and acknowledge reviewers. Good, timely reviews are rewarded with a discount off their next MDPI publication. By creating an account on the submission system, reviewers can access details of their past reviews, see the comments of other reviewers, and download a letter of acknowledgement for their records. This is all done, of course, within the constraints of reviewer confidentiality. Feedback from reviewers shows that most see their task as a voluntary and mostly unseen work in service to the scientific community. We are grateful to our reviewers for the contribution they make.

Andres, Anne-Catherine
Barucca, Marco
Belo, José António
Bürglin, Thomas R.
Bush, Jeffrey
Chen, Yiping
Chirumbolo, Salvatore
Dykes, Iain M.
El-Bialy, Tarek
Enzmann, Volker
Fraser, Stuart T.
Fukai, Tohru
Greenfield, Andy
Guehring, Thorsten
Hadri, Lahouaria
Han, Jingjia
Han, Jinnuo
Harfe, Brian D.
Heilig, Juliane
Heissig, Beate
Horsley, Valerie
Huber, Paul W.
Immink, Richard
Januschke, Jens
Jaźwińska, Anna

Kappen, Claudia
Kashimada, Kenichi
Kawamata, Shin
Kiminobu, Sugaya
Klein, David C.
Kmita, Marie
Kouskoff, Valerie
Koyama, Tomotsugu
Krum, Susan A.
Kusumi, Kenro
Lafontant, Pascal J.
Lai, Wen-Fu Thomas
Li, Hongda
Lien, Ching-Ling
Loeken, Mary R.
Monaghan, James R.
Monte-Alto-Costa, Andréa
Mukhtar, M. Shahid
Muneoka, Ken
Muñoz-Chápuli, Ramón
Nawshad, Ali
Neri, Simona
Nichols, Joan E.
Niu, Jingwen
Niyibizi, Christopher

\author{
Noël, Emily S. \\ Oakes, Samantha \\ Pavlov, Youri I. \\ Porcher, Catherine \\ Pusapati, Ganesh \\ Roegiers, Fabrice \\ Rothuizen, Tonia C. \\ Shinoka, Toshiharu \\ Sima, Jian \\ Sommerville, John \\ Sparatore, Bianca \\ Tawil, Bill J. \\ Thomas-Chollier, Morgane \\ Tuan, Tai-lan \\ van Beuningen, Henk M. \\ Vaughan, Melville \\ Walsh, William R. \\ Yamazaki, Jun \\ Yang, Tao \\ Yang, Wan-Xi \\ Yang, Ye \\ Yano, Tohru \\ Zhang, Donghui \\ Zhou, Jun \\ Zorn, Aaron
}

(C) 2016 by the author; licensee MDPI, Basel, Switzerland. This article is an open access article distributed under the terms and conditions of the Creative Commons by Attribution (CC-BY) license (http://creativecommons.org/licenses/by/4.0/). 